\title{
Lecturers' Self Perception of Change in their Teaching Approaches: Reflections on a Qualitative Study
}

Roisin Donnelly

Technological University Dublin, roisin.donnelly@tudublin.ie

Follow this and additional works at: https://arrow.tudublin.ie/ltcart

Part of the Education Commons

\section{Recommended Citation}

Donnelly, R. (2008)Lecturers' Self Perception of Change in their Teaching Approaches: Reflections on a Qualitative Study, Educational Research, Vol. 50, Issue 3, 2008. DOI:10.1080/00131880802309317

This Article is brought to you for free and open access by the Learning Teaching \& Assessment at ARROW@TU Dublin. It has been accepted for inclusion in Articles by an authorized administrator of ARROW@TU Dublin. For more information, please contact arrow.admin@tudublin.ie, aisling.coyne@tudublin.ie, gerard.connolly@tudublin.ie.

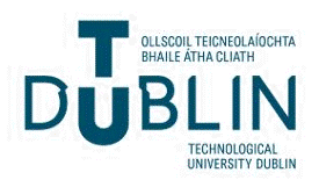




\title{
Lecturers' Self Perception of Change in their Teaching Approaches: \\ Reflections on a Qualitative Study
}

\author{
Roisin Donnelly \\ The Learning and Teaching Centre \\ Dublin Institute of Technology \\ Ireland \\ Email: Roisin.Donnelly@dit.ie
}

Tel: 0035314027886

\begin{abstract}
Background

Within the realm of teaching in higher education (HE), in this new millennium, there is currently no professional training requirement for teachers in Ireland; as a result the majority of teachers in Irish higher education do not have any teaching qualifications, and essentially are required to learn on the job, oftentimes relying on how they were taught themselves. However, there is growing recognition within the sector for the need for training for lecturers and other academic staff who have a teaching component to their work.
\end{abstract}

\section{Purpose}

The principal aim of this study is to explore the self perception of change in teaching approaches by lecturers who have graduated from a Postgraduate Certificate in Third Level Learning and Teaching Programme. 


\section{Programme description}

This is an evaluation study investigating the experiences of the graduates of the programme over a period extending from its inception in 2000 until 2003. The programme runs in an academic year, and has two modules: learning and teaching in higher education, and designing curricula and assessment strategies.

\section{Sample}

The study involved 45 successful graduates of the programme, who were teachers in a variety of higher education institutions around Ireland. These programme participants had a variety of experiences in HE teaching ranging from one year to 25 years, and hailed from a diverse mix of subject disciplines, encompassing apprentice, undergraduate and postgraduate education.

\section{Design and methods}

A qualitative questionnaire was distributed to the 45 participants to establish the difference that the programme has made on these lecturers' professional practice. The initial qualitative study was conducted in 2005, with a second stage completed in 2007.

\section{Results}

For this study, twenty five lecturers returned completed questionnaires; all indicated that change had taken made in their teaching approaches, and a number of alterations had taken place. Some of these claims lacked evidence and others provided evidence to 
support it. The most significant changes identified were increased reflection on current teaching approaches, the introduction of new teaching strategies, increased focus on the design and delivery of classes, more work taking place on course teams, an increase in confidence about learning and teaching and a more student-centred approach taken to teaching.

\section{Conclusions}

The changes in teaching approaches for these individuals has been multidimensional and include the design of new instructional strategies, the use of new teaching approaches, and the alteration of beliefs (pedagogical assumptions and learning theories) about learning and teaching in higher education. These findings are significant for the programme team and future participants in that they can be used to support this model and the teaching strategies and format of the programme as it presently stands. In a wider frame, they are important to allow academic staff to realize opportunities to join forces with others in their departments, and show them that they are part of a larger movement to develop a learning society through their work with students.

\section{Keywords}

Academic Professional development; Educational change; Learning and teaching; Programme evaluation; Teaching portfolio 


\section{Context of Study}

This evaluative research study was conducted to gauge the self perceptions of change by academic staff on teaching approaches (if any) of a Professional Development programme, namely the Postgraduate Certificate in Third Level Learning and Teaching. This is an accredited programme for higher education teachers in Ireland. The research has extended over a period extending from 2000-2003. The third level (higher) education system in Ireland is broad in scope and encompasses the university sector, the technological sector (Institutes of Technology), the colleges of education and private, independent colleges. The institutions which fall within the first three groupings are autonomous and self governing, but substantially state funded.

In this case, the programme is located within a Faculty of Academic Affairs in an Institute of Technology. Each year, programme participants are drawn from very diverse fields and have spent varying lengths of time as lecturers there are a range of programme participants, from newly appointed staff to the institution, to those that have been teaching for anywhere between 5-25 years. Our experience of working with the participants is that this multi disciplinary setting provides for interesting and critical discourse about teaching and learning. In terms of their subject disciplines, there is an eclectic mix, with many subject disciplines being represented: apprentice education, undergraduate and postgraduate education: aeronautical engineering, architecture, art and design, bakery studies, biology, business studies, chemistry, economics, electrical engineering, fabrication and welding, fashion and textiles, film and media studies, graphic design, home economics for teacher education, hotel and catering management, 
IT Staff Development, marketing, music, nurse tutoring, optometry, professional cookery, physics, science librarian, social care, transport engineering, visual communication. Participants also include librarians, IT trainers and other academic support staff. All participants are self-selecting and choose to come on the programme.

Since 2001, the programme is also offered to appropriate staff of universities and other institutes of technology throughout Ireland. This is in line with the recommendations of the Colloquium on University Teaching and Learning held in Dublin in December 1998, whose recommendations included one which sought "to facilitate further interinstitutional collaboration in development of a core curriculum for the professional development of staff' (Colloquium 1998, 10). Rowland (2001) concludes from the experience of working with different groups of lecturers that they learn much from each other by drawing upon these differences and that the mixed grouping allows for practices and assumptions to be challenged by others from different backgrounds and this echoes the experience of tutors on this programme.

There is currently no professional training requirement for higher education teachers in the Republic of Ireland as far as their teaching is concerned, and the majority of teachers in higher education in the Republic of Ireland do not have any teaching qualifications, and essentially are required to learn on the job. However, there is growing recognition within the sector for the need for training for lecturers and other academic staff who have a teaching component to their work. 
There has been a growth in the demand for similar programmes internationally and on the island of Ireland. Both universities in the North of the country (The University of Ulster and The Queen's University Belfast) have postgraduate teaching certificates which predate this current programme. Indeed, discussions took place with colleagues from both institutions in the early stages of our programme to better inform the design team's thinking. In many institutions the certificate level qualification is mandatory for new staff. In some countries these programmes are also linked to membership of professionally recognised learning and teaching organisations. Some of the programmes receive accreditation from an external agency in addition to institutional accreditation. As part of the educational needs analysis for this new programme, many of these fellow programmes were reviewed.

Over the past number of decades, the decline in teaching in favour of research in most institutions of higher education has helped lower the status of teacher education. This past trend had the effect of leaving academic staff confused over the mission of higher education and uncertain of their role in it. Fullan $(1993,104)$ maintains that a high quality teaching force, always learning, is the sine qua non of coping with dynamic complexity; there are no substitutes to having better teachers. It is all about making the career-long continuum of teacher learning a reality.

At the point of where the study was completed, there have been 45 graduates from the programme. Arguably, this is quite small scale but in terms of this institution, is substantial in terms of numbers of participants on the programme to have an impact on 
the ground. Fullan $(1993,40)$ has suggested that "moral purpose needs an engine, and that engine is individual, skilled change agents pushing for changes around them, intersecting with other like minded individuals and groups to form the critical mass necessary to bring about continuous improvements."

\section{Rationale for Programme Evaluation}

There have been a number of existing reviews of such programmes, at almost a decade apart (Carroll, 1980; Wulff and Szego, 1989; Weiner and Lenze, 1997). However, it can be argued that these reviews provide a lack of evidence and lack of theoretical underpinning, and have not added sufficiently to the area. Rust (2000) reported lack of interest in researching the value of such programmes. Since then, educational developers in Stockholm University have conducted recent empirical research into how first-level programme participants, whose training in university pedagogy is compulsory, consider their teaching has changed since programme completion (Adamson and Duhs, 2004). Their focus has been how they can extend the impact if their work to embrace more members of the university community, and how teachers can gain departmental support for innovative steps to improve student learning.

Similarly, the experiences of lecturers completing a teacher training certificate at South Bank University have been captured in research from its 1992 inception (Britton, 2004). This study raised some interesting issues in conducting such insider research; might respondents give "right answers" to please us? And what of the "problem of maintaining 
the balance between the level of detachment we would aspire to as researchers and the support we would wish to offer as educational developers" (McDowell 1996, 140).

Whilst acknowledging that this is an issue, it is argued here that such insider research is valuable because it draws on the experience of practitioners as complete members of their organizations and so makes a distinctive contribution to the development of insider knowledge about organizations and organizational change. An important message from Newton's research (2001) is that there are considerable merits in close-up study and insider research into 'views from below', and that there is scope for much wider application in a variety of higher education contexts and work environments.

A research study into initial teacher training programmes in higher education at the University of Sussex used a model based on the work of Ho, Watkins \& Kelly (2001) for assessing impact on a number of key areas: conceptions of teaching of programme participants, impact on teaching approaches, impact on student learning and impact on departments, and exploring what happens to programme participants when they return to the cultures of their home departments (Thew and Clayton, 2004).

This current Irish research can be placed in the context of a wider study by Gibbs and Coffey (2004) whose research looked at the impact of initial training programmes such as this in 22 universities in eight countries, and support for teachers in researching the impact of changes (to assessment, teaching or other aspects of course design) on student learning processes and outcomes. Some of the findings of this study revealed that trained 
teachers rated better on all six scales of the instrument used, but that the type of course made no difference on impact. The conclusions of this study suggest currently that there is very little empirical evidence concerning the impact of educational development practice; it recommends that it is not impossible to obtain evidence of impact and such evidence can be quite influential when credible. It is with these conclusions in mind, that this current study in an Irish context may be considered.

The research reported on in this paper does not extend to a consideration of actual measurement of impact of the programme as it has been suggested that any consideration of 'impact' needs to question the various agendas and (sometimes competing) discourses which educational development has supported, or in which it finds itself caught up. The assessment of impact must take account of the distinctive cultures in which we work and the contexts of organisational change we have to negotiate (Gibbs et al. 2004). It is argued here that this will form part of a wider research study across learning and teaching in the institution.

However, it is suggested that this research in an Irish context has implications for other such programmes delivered in the UK and further afield as it based on the premise that we need to analyse the pedagogical base for why we, as educational developers, do what we do - our underlying theories of learning and the rationales we offer for continuing, or changing, what we do. Ultimately, this research aims to address, for the learning and teaching centre involved, is its practice inherently valuable and who values it? 


\section{Specification of the Change Context}

The programme team of four educational developers (tutors) were responsible for designing and facilitating delivery of this programme. Working together within the programme team, we support over one thousand academic staff across the institution. Team teaching figures strongly in the moderation of the programme, and we favour teacher collaboration and collegiality for it is an area that we wished to promote to the teachers who came on the programme. We agreed that it is important to bring a variety of perspectives to the subject under consideration. All tutors are jointly responsible for programme content and assessment. However, they take turns presenting material appropriate to their individual areas of specialization. Careful planning is essential, and this approach depends for its success on the compatibility and mutual respect of those involved.

It was important to consider notions of change in this context. Within this study, it is the difference that the programme has made on these lecturers' professional practice as a result of successfully completing. It has been agreed amongst the programme team that the results of this study can be used to continue the process of design and facilitation of learning on the Postgraduate Certificate Programme. The results may also ultimately alter the attitudes and behaviour of the academic team who designed and deliver the programme.

Although currently, this is the first such programme designed specifically for academic staff in the higher education sector in Ireland, it is vital that this programme is evaluated 
and reviewed to ensure that it is meeting its objectives as in the coming years, as there will be a number of similar programmes being delivered from higher education institutions around the country. As a result of this, it was felt by the programme team to be no longer sufficient to study factors associated with the success or failure of such an innovation as this programme is in Irish higher education.

\section{Programme Structure and Pedagogy}

The programme was designed with two core modules in mind, 'Learning and Teaching in Higher Education' and 'Designing Curricula and Assessment Strategies': practical details being that each module is of 15 weeks duration, and the participants meet for a face to face class session for 3 hours of each of these weeks and independent learning is fully encouraged outside of this schedule. An overall goal of the programme is that it acts as a catalyst within the various institutions represented, encouraging these lecturers to reflect on all aspects of the learning, teaching and assessment provision.

The aim of Module One is to provide teachers in higher education with a wide range of practical learning and teaching methods, including the use of relevant learning technologies that will help their students learn more effectively. The second module is an introduction to curriculum design and assessment strategies. The aim of the module is to facilitate lecturers to take a competent active role in the development of high quality curricula and appropriate assessment strategies in their own contexts. 
The two modules on the programme are assessed through the development and production of a Teaching Portfolio. A definition of the nature of the Teaching Portfolio required for this programme is provided early in the first module to the participants. It is to be a tightly written, reflective collection of work, summarising a teacher's approach to learning and teaching, and providing evidence of major teaching activities and accomplishments. It is to be constructed by the participants to highlight and demonstrate their knowledge and skills in teaching in higher education.

\section{The Evaluation Study}

There is an argument that participation on such a programme as this may divert participant's energies away from research, and perhaps ultimately damage their career prospects in academia. However, this paper argues that continuous professional development (CPD), such as this programme, for academic staff in higher education can increase the extent to which teachers adopt a student centred style to their teaching approaches. A student centred approach is known to be associated with students taking a deep approach to a greater extent and hence to improved quality of student learning outcomes (Gibbs and Coffey 2004, 98).

Studies into teacher professional development have shown that teaching is valued and the improvement of teaching encouraged. Innovation and change are supported and openly discussed. Teachers who completed accredited programmes were demonstrably better than those who undertook no such accredited training (Gibbs and Coffey 2004, 99). 
Over the past number of decades, internationally, the decline in teaching in favour of research in most institutions of higher education has helped lower the status of teacher education. This past trend had the effect of leaving academic staff confused over the mission of higher education and uncertain of their role in it. Whilst acknowledging the importance of research, within the Republic of Ireland, the primacy of the teaching role in the life of the academic has been asserted in a government-commissioned report.

The status and prestige of research notwithstanding, according to the Carnegie Commissions international survey of the academic profession, teaching students emerged very strongly as the principle defining characteristic of the academic.

(Skilbeck 2001, 72)

Dalin (1993) and Trowler (1998), amongst many others, have written about the change process in higher education. When change is attempted under certain circumstances, it can result in defensiveness, superficiality or at best short-lived pockets of success (Fullan 1993, 3). From the outset of this study, there has been an awareness of this, and by making such circumstances explicit to other members of the programme team, is an attempt to avoid this happening. Land (2001), Roche (2001), Stefani and Mathews (2002) have written about the role of the academic developer in the change process. However, the question of change in this paper is in broad relation to the individual teacher and practice, the teacher's department and, to a narrower extent, the academic culture in the institution.

Insert Figure 1 here 
The data sources for this study are graduates from the 2000-01 cohort, 2001-02 cohort, and 2002-03 cohorts of the Postgraduate Certificate. In terms of sampling for the study, it has been identified that all the past participants are important to contact because the aim of the study is to gauge the self perception of change that the programme has had over a wide variety of subject disciplines in higher education.

Insert Table 1 here

The questionnaire consisted of a number of closed and open-ended questions, so, it allowed the participants to include their opinions and judgments of the impact of change that the programme has had on their teaching approaches alongside statements of perception about change occurring. The data types to be collected include a range of facts, attitudes, opinions, perceptions about the Postgraduate Certificate Programme. One question was designed using a five point likert scale to measure the self perception of change in practice by specific classes on the programme.

Insert Table 2 here

\section{Results}

From the 45 questionnaires that were sent out to the graduates of the programme, 25 were returned; 5 from the 2001 cohort responded, 7 from the 2002 cohort responded and 13 from the 2003 cohort responded. 
With regards to Question 1, twenty graduates found their departments supportive of learning and teaching; a quote from one of the respondents illustrates the support from peers and management:

Freedom is given to implement new strategies; colleagues are interested in new ideas; funding is also given for attendance on the L\&T course.

Positive encouragement by Dept Head and peers; timetable adjustments made to facilitate attendance and follow-up study of L\&T courses; discussions take place on teaching methods.

However, when provided with the opportunity to expand on support levels, some respondents provided different perceptions on management support of learning and teaching:

Very uninterested in discussing, changing, supporting or researching student learning; curricula change only happens at individual level; no meetings or internal discussion with $H / D$ about student work, teaching contexts etc; no grants offered for staff to train.

It does not come into what they do; too partial, bitty; based on personalities and their initiatives; no concerted departmental efforts that are resourced and pushed on by political will.

A question was included regarding the identification by respondents of the main themes regarding a course philosophy. This was answered positively by 21 respondents and emerging themes were

constructivist active student learning and reflective teaching approaches

All 25 graduates responded positively to questions 3 and 6 respectively that their teaching approaches had changed over what it was before doing the programme, and that 
completing the programme was of benefit to their institutions. Some aspects of this change were highlighted as:

More student oriented; using a wider range of teaching methods.

Better planner; constantly reflecting on my practice and looking at different methods.

More group work; focus on student learning outcomes; less prescriptive approach; better assessment process; more empathy with students; perhaps more respectful of students; more participation from students in class time.

Use of lesson plans and evaluation; incorporate more interactivity and small group work; keep the learning student centred and experiential where possible; use of reflection to pinpoint changes needed.

Eighteen graduates responded positively to question 4 that they had seen change in their own students' learning as a result of their changed practice.

The structured activities in lectures mean that the students are involved and are attempting to apply what they have learned instead of sitting back listening; students who have been present for these activities usually pass related questions on the assessment tests during the year.

Ten graduates responded positively to question 5 that their role in the department had changed since undertaking the programme; but several acknowledged that this is difficult in itself to attribute to one factor alone, such as having completed this programme:

A higher number of requests for classes but could be coincidence; have been nominated to the Science Faculty T\&L committee.

There were a number of findings from the secondary questions included in the questionnaire to establish the nature of change to participants' teaching approaches, as a 
result of having completed the two main programme assessments: a teaching portfolio and a group project. They can be categorised as:

- Reflection on current teaching approaches;

- New teaching strategies;

- Design and delivery of class;

- Work on programme teams;

- Increased confidence;

- More student-centred approach.

A likert scale used to measure the range of impact on teaching approaches from 1-4 (no impact to strong impact) yielded that the following classes experienced on the programme had the strongest impact on participants teaching approaches.

Insert Figure 2 here

As Figure 2 shows, 20 lecturers responded that each of the two classes 'Making Teaching more Interactive' and 'Assessment Strategies' made most impact on their practice; with 'Lecture Design and Delivery', 'Lesson Planning' and 'Curriculum Design Models' being a close second with 19 responses each.

\section{Discussion of Self Perception of Change}

"Public evaluation should be an institution for democratizing public decision making...[serving] the interests of the larger society and of various groups within society, particularly those most affected by the program under review" (House, 1990). The nature 
of change from all 25 respondents was cited as improvement/benefit in their teaching approaches and/or the learning environment. Figure 3, below, adapted from Fullan, cited in Bennett et al. $(1992,126)$ illustrates the responses from question 17, and how these can be interpreted as contributing towards changed teaching approaches:

Insert Figure 3 here

It was important to establish the impact the programme had made on these lecturers' thinking, planning and professional practice.

\section{Thinking/Planning}

You become less concerned with the content although that is important and reflect more on why you are teaching what you are teaching, how it links to everything else and the most appropriate way to present it to a particular group of students.

I now think about the learning rather than the teaching and that make me think about the best way I as a teacher can enhance the learning experience. I certainly reflect more on what I do.

I question much more what I do, why I am doing it and what the students will get from it. 
Practice

I have developed skills and knowledge to deliver and organise better lectures and tutorials but the most important professional development has been gaining an understanding, awareness and ability to question myself about the approaches I use in teaching and ask myself why I do it and could I do it more effectively?

There is no doubt that educational change is a dynamic process involving interacting variables over time. The lecturers' response to this questionnaire on the self perception on their teaching approaches of having completed the Postgraduate Certificate programme has been given in hindsight, over a period of 1-3 years. Fullan (cited in Bennett et al. 1992, 112) states that any change can be examined with regard to difficulty, skill required, and extent of alterations in beliefs, teaching strategies, and use of materials. The innovations cited by the respondents were largely curriculum or classroom focused changes. The characteristics of the changes can be looked at in terms of their size, complexity, prescriptiveness and practicality for the teachers involved. Simple changes may be easier to carry out, but they may not make much of a difference. Practical changes are those that address salient needs, that fit well with the teachers' situation, that are focused and that include concrete how-to-do-it possibilities. Successful organisations are those that encourage cultural change and improve organisational effectiveness through the development of a shared vision which is seen to emerge from the personal visions held by individuals within the organization (Broadbent, 1998).

The individual teacher's characteristics can play a role in determining implementation of change. Some teachers, depending on their personality, and influenced by their experiences on this programme, are more self-actualised and have a greater sense of 
efficacy, which leads them to take action and persist in the effort required to bring about successful implementation of change. In the final analysis, according to Fullan (cited in Bennett et al. 1992, 117), it is the actions of the individual that count. All participants on the programme were aware that change involved learning to do something new. This, alongside having a work environment that could stimulate continuous improvements was an important factor emerging from this research.

Within this, there is also attentiveness to the idea that almost every important learning experience we have ever had has been stressful. This means that the capacity to suspend belief, take risks and experience the unknown are essential to learning. Under conditions of uncertainty, learning, anxiety, difficulties and fear of the unknown are intrinsic to all change processes, especially at the early stages (Fullan 1993, 25). As indicated by some of the respondents, some form of conflict is essential to any successful change effort; change itself is learning.

It was a very painful process for me; I examined my mind like never before. My beliefs were not all misguided. My equality paper was good therapy. My recording of new teaching approaches was enlightening and I also received valuable feedback from peers and tutors to guide me along the way.

The year presented challenge after challenge for me but there is no doubt now that the 'light bulb' has been lit! Hopefully more illumination is around the corner.

The participants can be more selective in what they try (as distinct from accepting all change) but in exploring selected new ideas, they must be patient enough to learn more about them and to look for longer term consequences before drawing conclusions (Fullan 1993, 17). 
Developing a personal philosophy of teaching, which is informed by and contributes to the organizational, community, societal and global contexts of education is an important facet of the work of the Postgraduate Certificate Programme. When these teachers work on personal vision-building and see how their commitment to making a difference in the classroom is connected to the wider purpose of education, it gives practical and moral meaning to their profession. The programme uses the Teaching Portfolio as a vehicle to get them started on this, by enabling them to pursue learning through constant inquiry; thereby they are practicing what they preach, benefiting themselves and their students by always learning.

When one teacher collaborates with another, or many teachers work in a new alliance with each other and external partners, they are enlarging their horizons as they lengthen and strengthen the levers of improvement. When many educators act this way, systems start to change, and according to Fullan $(1993,145)$ become the environments that prod and support further growth and development.

However, with all the emphasis we place on collegiality and collaboration, the capacity to think and work independently is also essential to educational reform. Meaningful reform can escape the typical teacher in favour of superficial, episodic reform (Fullan 2001, 36). It is important for these teachers to be aware of false clarity whereby they think their practice has changed, but it has only occurred in a superficial way. This point can be made to future participants now as a result of this study. 


\section{Forward Momentum of Academic Continuing Professional Development (CPD)}

Increasingly in the global education arena today, higher education institutions are developing both their HR policy and learning and teaching strategies with regards to the provision of CPD staff development programmes. For example, along with defining professional development, the University of Auckland (2004) has widened the scope of its policy to include alongside the prevalent need for research development, that of teaching development. Within the UK, support for CPD has expanded to include teaching excellence awards which have been added to the range of opportunities accessible for lecturers to demonstrate their commitment to teaching. Institutional programmes accredited by the Higher Education Academy are available in most institutions to providing generic and subject-specific training in learning, teaching and assessment for all new teaching staff. Reflecting all of these developments, King (2004) has argued that CPD is currently high on the agenda for UK higher education. Whilst her research has shown that CPD takes many forms, she highlights a number of key factors for its success: it needs to be recognized and rewarded, be collaborative, self-directed and contextualized.

In Ireland also, CPD for academic staff has emerged as the new driver underpinning teaching excellence. The University of Ulster recently (2007) developed its Codes of Practice because it had become apparent that there was a need to clarify a number of key principles in relation to CPD. Indeed in this current programme, the role of CPD for teaching staff has risen to the fore; the Postgraduate Certificate in Third Level Learning 
and Teaching, it has recently (2007) become mandatory for all new academic staff to attend within the first two years of beginning their post.

This current two phase qualitative study contributes to this context by offering insights on staff learning on the programme at all stages of the academic career, from novice through to experienced lecturer. The conducting of this piece of evaluation research was very timely. A full review of the three year Programme in Third Level Learning and Teaching (Certificate, Diploma, and Masters) took place in May 2005. This small-scale evaluative research complemented the full programmatic review. Since then, in 2007, a second phase to the research was conducted to augment the evaluative data. Two semi-structured focus groups were held with a selection of the original study participants in order to capture the participants' own thoughts and experiences of the teaching approaches they implemented in their classroom practice and to facilitate further dialogue with these colleagues on how this programme can be delivered into the future; this provided support for assumptions and conclusions about the programme and its effectiveness. The two focus group interviews allowed for a participant perspective based on their own generated learning from the programme to emerge.

The use of the focus-group method has expanded rapidly during the past decade or more and Kreuger (1994) in agreement with Morgan $(1997,2)$ asserts that the hallmark of this method is their explicit use of group interaction to produce data and insights that would be less accessible without the interaction found in a group. Kitzinger (1996) has reported that this method is most effective when the aim is to investigate the way knowledge and 
ideas develop within a certain context. Within this discourse model of collecting data, meaning and experience were formed, not merely expressed or reported, through the speaking that took place in the focus group process.

In each focus group interview there were between five to seven individuals and each were held immediately after the programme ended. The immediacy of the focus group session was designed to keep the sense that the participants felt that they were in the CPD classroom rather than in a different territory. My aim as moderator of these interviews was to be non-directive, allowing the group discussion to develop its own dynamic and pursue topics as they arose and captured the interest of the group. Stewart et al. (2007) suggest that the moderator is often quite nondirective with respect to the discussion, letting it flow naturally as long as it remains on the topic of interest. However, it was important to recognize that the amount of direction provided by myself as moderator does influence the types and quality of the data obtained. I found that I was not very directive in the focus group interviews in the sense of having to probe for more information on a given topic as the participants often stimulated one another's responses and even posed questions to one another. I did at times find myself encouraging the participants to shift positions from their role in the module as learners to their professional role as educators, in order to explore alternative perspectives, contradictions and ambivalences, where they occurred. The idea of shifting positions was important to show how the individual participant could hold different ways of interpreting their experience on programme. Investigating questions in the focus group interviews provided rich, or as Geertz (1973) termed it 'thick', detailed data which was valuable to complement the original evaluative data. Charmaz (1995) believes "rich data reveals thoughts, feelings and actions as well as 
context and structure...affording the researcher a thorough knowledge of the empirical world or problem that is being studied" (33). I used open questions to invite the participants to be receptive and expansive and to make associations between different experiences on the programme and where possible, avoided questions that elicited yes or no answers. I also tried to avoid straightforward why questions because as Hollway and Jefferson (2000) pointed out, "they can invite intellectualisations or rationalizations of problems and are often uninformative in terms of the research questions" (26). There was a certain amount of difficulty in trying to direct the discussion to topics relevant to the research without disrupting the social dynamics of the group. Although having said this, I found I did recognize the value of free association (apparently illogical connections) that some of the participants seemed to favour. In doing so, I was attempting not to curtail the participants too early.

The second phase of the study using two focus group interviews (FG1 and FG2) gathered the views and perspectives of academics graduated from the programme with the intention that this knowledge will be helpful in shaping future developments in academic professional development in the institution.

This programme ensured that I had knowledge to design, implement and review my teaching approaches and it was a means of supporting staff learning for all staff groups directly involved in core academic process.

(Programme Graduate, FG1)

The main learning that I took away with me after the programme ended was that any changes I made to my teaching practice was underpinned by a scholarly and evidence-based approach.

(Programme Graduate, FG2) 
In order to develop an understanding of influences on the teaching approaches of these academics working in higher education, it was vital to unpack their motivations, intentions and actions as individuals in respect of continuing professional development. The guidance that a community of collegial discourse provides, such as present on the programme, can sustain one in the trials of learning. Palmer $(1998,144)$ believes "the growth of any craft depends on shared practice and honest dialogue among the people who do it."

Systematic, comprehensive staff development is a crucial requirement of the contemporary learning organization and there are many different ways of providing for it other than conventional short courses. However, worldwide, higher education institutions are using formal, accredited courses for academic staff as a vehicle for diffusion of staff development in learning and teaching. This study has suggested that alongside needing to acquire effective ways of facilitating learning and teaching, a change in attitude, values and beliefs will develop confidence for ongoing learning. In the past in my institution, professional development tended to have been short-term workshops, focused on general topics rather than deep knowledge of subject matter and pedagogy, disconnected from specific classroom practices and isolated from ongoing support from colleagues and tutors. This Postgraduate Certificate in Third Level Level Learning and Teaching offers committed teachers a place to find each other, talk with each other and discover ways to provide each other with continuing support. 
It is also important to consider what influences staff engagement and participation in teaching developments in order to shift practices at a rate that is appropriate for a department or institution. The issue of transferability of innovative approaches and developing the capacity to respond to innovation and change remains a key area for further research. Whilst this may appear to be an unpalatable position to take at times, realisation is required that for real and not just cosmetic change to take place, a whole range of well-established cultural tools needs to be re-created to transform the way that academic staff experience their professional development, specifically the existing established roles (the formation of new relationships of power and control between tutors and peers) and the use of time. Alongside this, regard should be given to the more successful models of academic development of how to support changes in teaching approaches.

\section{Conclusions}

Who benefits from this study? Will the types of impact outlined be beneficial to others? It is important also to consider the nature of the change itself - is it focused on the individual teacher or on the system? This study explored what effect the programme has produced amongst its graduates, but it is interesting to note if it is growing change agents, whereby in five to ten years time, change will happen in a significant way? By that time, there may be a critical mass of teachers, having successfully completed the programme and whose focus as a result is on improving learning and teaching in the practice of the whole department. 
This study relates to others in the field in that it is aimed at the preparation of educators in lecturer education programs in colleges of education and includes a vision of these teachers as architects of new directions for today's learning. Dissemination of these findings are equally valid in that it is important to describe what was learned through the process that we used. Often, as much can be learned from apparent 'failures' as from obvious successes.

The aim of the study was to measure the impact of change in teaching approaches for lecturers who have graduated from the Postgraduate Certificate Programme, over a period of three years. So, to what extent does the response to this questionnaire show curriculum and/or teaching approaches change as a result of having completed the Postgraduate Certificate Programme?

The findings of this study has revealed for the researcher that change in teaching approaches for these individuals has been multidimensional. There have been three main impacts on teaching approaches emerging as a result of having graduated from this programme: the design of new instructional strategies, the use of new teaching approaches, and the alteration of beliefs (pedagogical assumptions and learning theories) about learning and teaching in higher education.

These findings are significant for the programme team and future participants; this programme is based on an experiential model of learning, and these findings, in this research context, can be used to support this model and the teaching strategies and format 
of the programme as it presently stands; however, one suggestion proposed by a respondent, of having a class on reflective journals, is a very useful one and can be implemented in the next run of the programme.

How are they important in the wider frame? Educational change has been a learning experience for all involved. These teachers still need to focus on making a difference with individual students, but they must also work on department-wide change to create the working conditions that will be most effective in helping all students learn. As revealed in the questionnaire responses, they must continue to look for opportunities to join forces with others in their departments, and must realize that they are part of a larger movement to develop a learning society through their work with students. It is only by these individuals continuing to take action to alter their own environments that there is any chance for deep change.

It is necessary for the Centre to continue to redesign the programme to focus directly on developing the beginner and experienced teacher's knowledge base for effective teaching and the knowledge base for making changes in the conditions that affect teaching. We need to keep asking ourselves: "are a large percentage of these educators thoroughly grounded in the knowledge and skills required to bring about meaningful change?" Goodlad (1991, cited in Fullan 1993, 119).

In terms of how we see ourselves in the Centre, Sarasen (cited in Fullan 1993, 120), has captured its essence: "as long as educators see themselves as lacking the power to 
change anything in a meaningful way, they will remain part of the problem." The development of a knowledge base for change within our Centre is a powerful potential asset for altering the quality and the status of teacher preparation.

In terms of the institution, it needs to be actively plugged into its environment responding to and contributing to the issues of the day. There is little doubt that Irish society as a whole is profoundly affected by the growing international culture of globalization and by a wide array of cultural, social and economic change forces affecting education (Skilbeck 2003, 5). Forces within the country and in the international environment have already combined to ensure a culture of continuing change. The challenge, according to Skilbeck $(2003,2)$, is "to face the issues squarely and to demonstrate that tertiary education in all its forms and manifestations is capable of strategic innovation and creative problem solving." Seeing 'our connectedness to the world' and helping others to see it is a moral purpose and teaching/learning opportunity of the highest order (Fullan 1993, 39). This programme will continue to strive to achieve this.

\section{Future Work}

A larger study needs to focus on the development of personal strategies by individuals to respond to, and seek to influence the impact of continued structural and cultural change in the HE sector in Ireland. Teachers with a moral purpose will always be key players in any progress made in educational reform (Fullan, 1999, 84). As this current two-phase study has shown, adoption of changed practice has taken place in a number of subject areas; the future research needs to address if this throws light upon the problems of change in 
learning and teaching around this institution. Small scale improvement will not last if we do not identify with and help improve the surrounding system (Fullan 2001, 272). 


\section{References}

Abbott, R.D., Wulff, D.H. and Szego, C.K. 1989. Review of research on TA training. In New Directions for Teaching and Learning: Teaching Assistant Training in the 1990s, eds. J.D. Nyquist, R.D. Abbott and D.H. Wulff. San Francisco: Jossey-Bass.

Adamson, L. and R. Duhs. 2004. Spreading good practice or struggling against resistance to change: how are we doing? Issues from a Swedish case. Paper presented at $9^{\text {th }}$ Annual SEDA Conference for Staff and Educational Developers: Questioning the Impact of Staff and Educational Development, November 16-17, in Novotel, Birmingham Centre.

Bennett, N., Crawford, M. and Riches, C. eds. 1992. Managing Change in Education: Individual and Organisational Perspectives. London: Open University Press.

Britton, A. 2004. "Is it really worth doing? The impact of an initial training course in university teaching. Paper presented at $9^{\text {th }}$ Annual SEDA Conference for Staff and Educational Developers: Questioning the Impact of Staff and Educational Development, November 16-17, in Novotel, Birmingham Centre.

Broadbent, C. 1998. Transforming the University: Tensions and opportunities for academics. http://www.aare.edu.au/98pap/bro98142.htm.

Carroll, J.G. 1980. Effects of training programs for university teaching assistants: a review of empirical research. Journal of Higher Education 51, no. 2: 167-183. 
Charmaz, C. 1995. Grounded Theory. In Rethinking Methods in Psychology, eds. J.A. Smith, R. Harré and L.Van Langenhove. London: Sage.

Colloquim 1998. University Teaching and Learning: Policy and Practice. Dublin: Royal Hospital Kilmainham.

Dalin, P., Rolff, H., and Kottkamp, R. 1993. Changing the School Culture. London: Cassell.

Fullan, M. 1993. Change Forces. Probing the Depths of Educational Reform. London: Falmer Press.

Fullan, M. 1999. Change Forces. The Sequel. London: Falmer Press.

Fullan, M. 2001. The New Meaning of Educational Change. London: Routledge Falmer.

Geertz, C. 1973. The Interpretation of Cultures. New York: Basic Books.

Gibbs, G. and Coffey, M. 2004. The impact of training university teachers on their teaching skills, their approach to teaching and the approach to learning of their students. Active Learning in Higher Education 5, no. 1: 87-100. 
Gibbs, G., Land, R. and McAlpine, L. 2004. Questioning the impact of Staff and Educational Development - Starting a Debate, Opening Plenary $9^{\text {th }}$ Annual SEDA Conference for Staff and Educational Developers: Questioning the Impact of Staff and Educational Development, November 16-17, in Novotel, Birmingham Centre.

Guba, E. and Lincoln, Y. 1989. Fourth Generation Evaluation. London: Sage Publications.

Ho, A., Watkins, D., and Kelly, M. 2001. The conceptual change approach to improving teaching and learning: An evaluation of a Hong Kong staff development programme. Higher Education 42: 143-169.

Hollway, W. and Jefferson, T. 2000. Doing Qualitative Research Differently: Free Association, Narrative and the Interview Method. London: Sage.

House, E.R. 1990. Methodology and Justice. In Evaluation and Social Justice, ed. K.A. Sirotnik, 23-36. San Francisco: Jossey-Bass.

King, H. 2004. Continuing Professional Development in Higher Education: What do academics do? Planet No.13 http://www.gees.ac.uk/planet/p13/p13_8.pdf.

Kitzinger, J. 1996. Qualitative Research. Introducing Focus Groups. British Medical Journal 311: 229-302. 
Kreuger, R.A. 1994. Focus Groups. A Practical Guide for Applied Research. Newbury Park, CA: Sage Publications Inc.

Land, R. 2001. Review of research on TA training. Agency, context and change in academic development. The International Journal for Academic Development 6, No.1: 4-20.

McDowell, L. 1996. A Different Kind of R\&D? Considering Educational Research and Educational Development. In Improving Student Learning: Using Research to Improve Student Learning, ed. G. Gibbs. Oxford: Oxford Centre for Staff Development.

Morgan, D.L. 1997. Focus Groups as Qualitative Research. Newbury Park, CA: Sage Publications Inc.

Newton, J. 2001. Views from below: academics coping with quality. Keynote presentation at the $6^{\text {th }}$ QHE Seminar in association with EAIR and SHRE. Birmingham, UK.

Palmer, P. 1998. The Courage to Teach: Exploring the Inner Landscape of a Teacher's Life. San Francisco, CA: Jossey-Bass.

Roche, V. 2001. Professional Development models and transformative change: A case study of indicators of effective practice in higher education. International Journal for Academic Development 6, No. 2: 120-129. 
Rowland, S. 2001. Surface learning about teaching in higher education: The need for more critical conversations. The International Journal for Academic Development 6, No. 2: $162-167$.

Rust, C. 2000. Do initial training courses have an impact on university teaching? The evidence from two evaluative studies of one course. Innovations in Education and Training International 37, No. 3: 254-262.

Scriven, M. 1967. The Methodology of Evaluation. In Perspectives of Curriculum Evaluation, eds. R.W. Tyler, R. M. Gagne and M. Scriven. Chicago, IL: Rand McNally.

Skilbeck, M. 2001. The University Challenged: A Review of International Trends and Issues with Particular Reference to Ireland. Dublin: The Higher Education Authority.

Stefani, L. and R. Matthew. 2002. The difficulties of defining development: a case study. International Journal of Academic Development 7: 41-50.

Stewart, D., Shamdasani, P. and Rook, D. 2007. Focus Groups: Theory and Practice. London: Sage Publications.

Thew, N. and S. Clayton. 2004. More bang for our buck? Using an impact assessment tool to enhance teacher training programmes. Paper presented at $9^{\text {th }}$ Annual SEDA 
Conference for Staff and Educational Developers: Questioning the Impact of Staff and Educational Development, November 16-17, in Novotel, Birmingham Centre.

Trowler, P. 1998. Academics Responding to Change: new higher education frameworks and academic cultures. Buckingham: Open University Press/SRHE.

Weimer, M. and L.F. Lenze. 1997. Instructional interventions: a review of the literature on efforts to improve instruction. In Effective Teaching In Higher Education: Research and Practice, eds. R.P. Perry and J.C. Smart. New York: Agathon Press. 


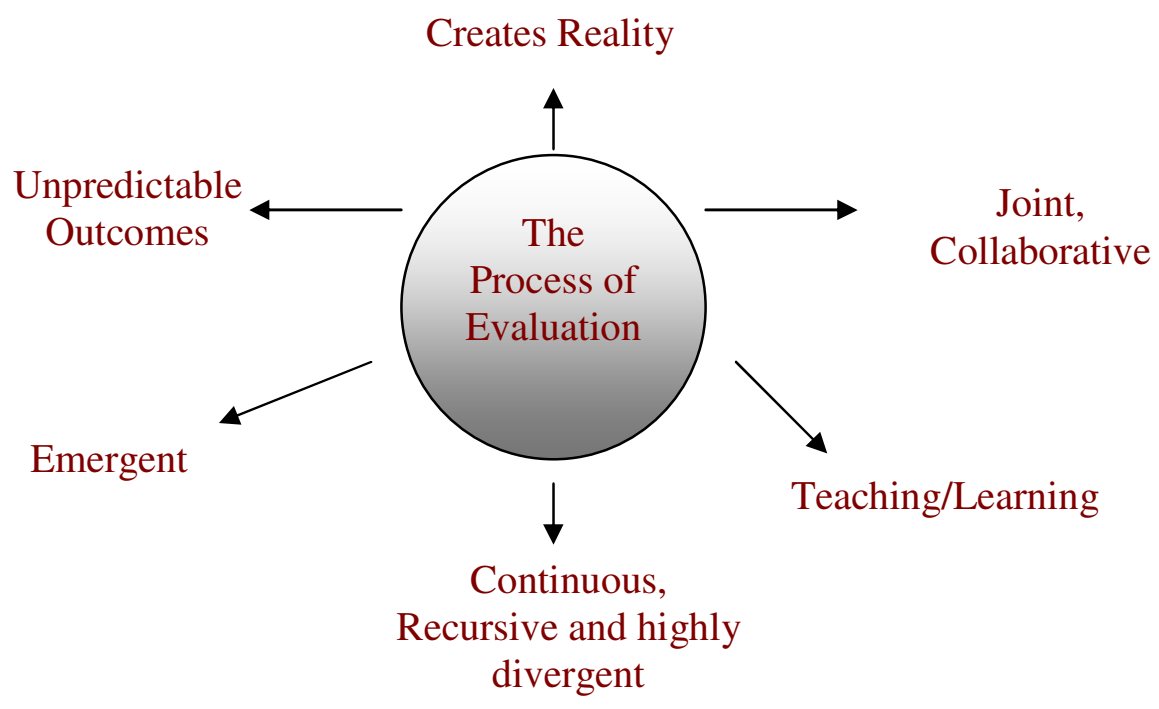

Figure I The Process of Evaluation 


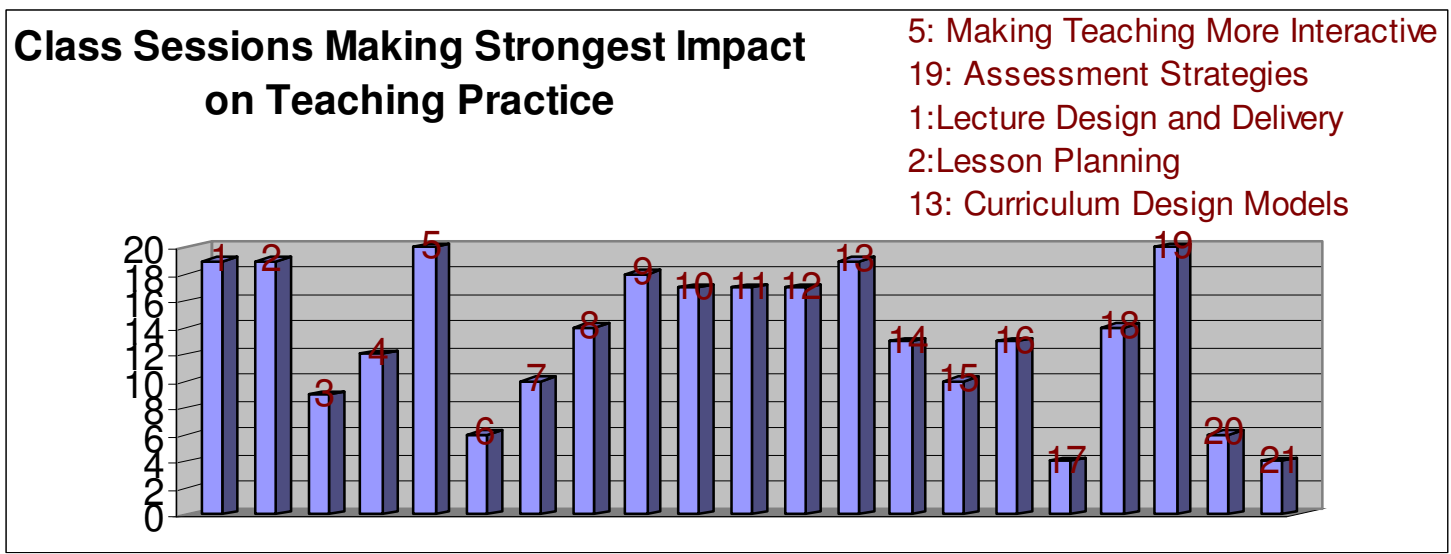

Figure II Analysis of Class Sessions on Teaching Approaches 


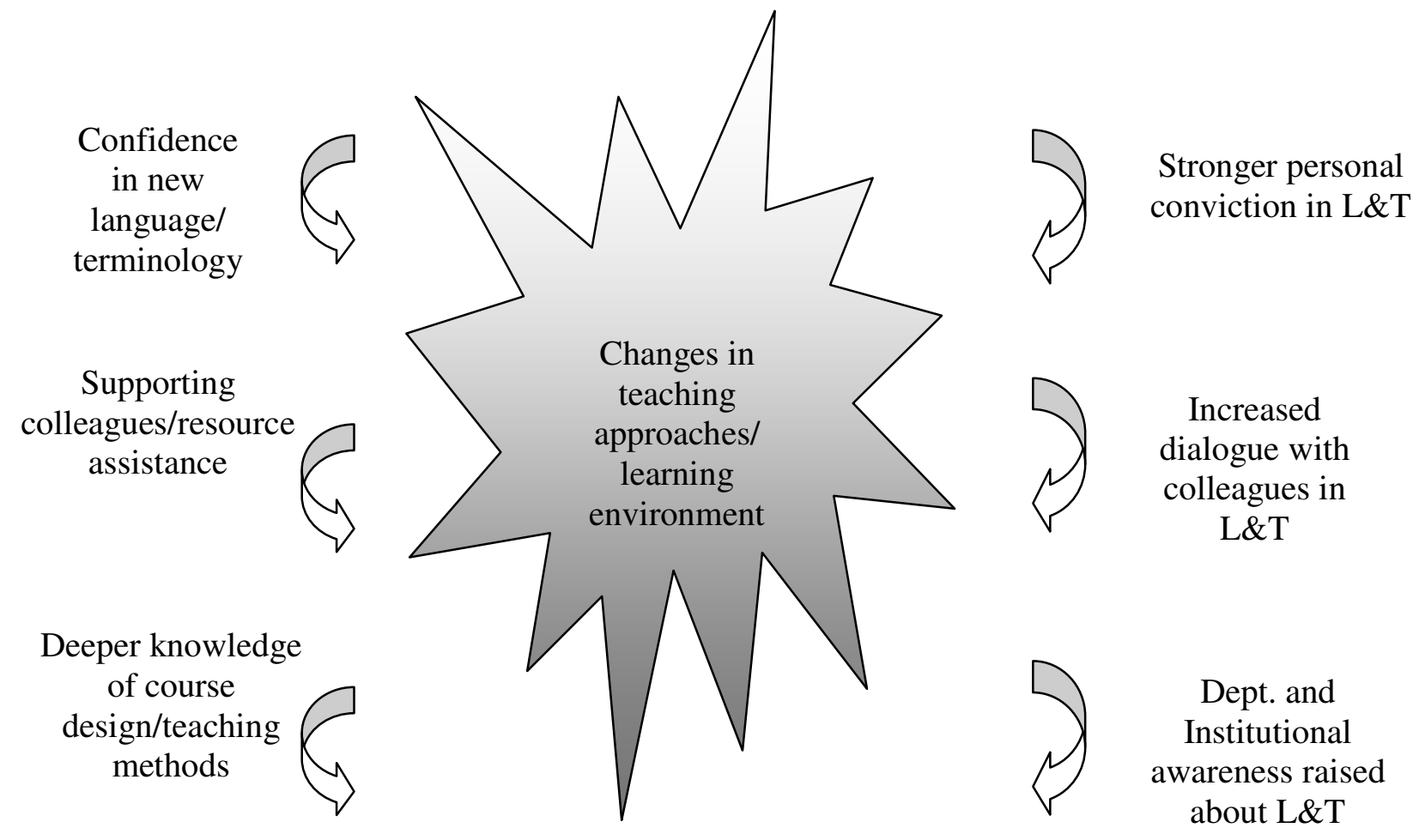

Figure III Changes in Teaching Approaches 


\begin{tabular}{|l|}
\hline 8 participants graduated in 2001 \\
\hline 12 participants graduated in 2002 \\
\hline 25 participants graduated in 2003 \\
\hline Total Sample Size $=45$ \\
\hline
\end{tabular}

Table 1 Sample Size 


\begin{tabular}{|l|l|}
\hline 1 & $\begin{array}{l}\text { In your opinion, generally, what do you consider your department's attitude to } \\
\text { learning and teaching to be (supportive / non-supportive) }\end{array}$ \\
\hline 2 & What was your motivation for doing the Postgraduate Certificate course \\
\hline 3 & $\begin{array}{l}\text { Have your teaching approaches changed over what it was before doing the } \\
\text { course - name specific changes }\end{array}$ \\
\hline 4 & $\begin{array}{l}\text { Have you seen change in your own students' learning as a result of your } \\
\text { changed practice - what evidence do you have for this change }\end{array}$ \\
\hline 5 & $\begin{array}{l}\text { Has your role in the department changed since undertaking the course } \\
\text { - name specific changes }\end{array}$ \\
\hline 6 & $\begin{array}{l}\text { Do you consider it to be a benefit to your school or institution by your having } \\
\text { successfully completing the course } \\
\text { - give examples of such benefits }\end{array}$ \\
\hline
\end{tabular}

Table 2 Selection of Qualitative Questions gauging self perception of change 